\title{
Fabrication and Characterization of ZnO Nanowire Arrays with an Investigation into Electrochemical Sensing Capabilities
}

\author{
Jessica Weber, ${ }^{1,2}$ Sathyaharish Jeedigunta, ${ }^{2,3}$ and Ashok Kumar ${ }^{1,2}$ \\ ${ }^{1}$ Department of Mechanical Engineering, University of South Florida, Tampa, FL 33620, USA \\ ${ }^{2}$ Nanomaterials and Nanomanufacturing Research Center, University of South Florida, Tampa, FL 33620, USA \\ ${ }^{3}$ Department of Electrical Engineering, University of South Florida, Tampa, FL 33620, USA \\ Correspondence should be addressed to Ashok Kumar, akumar@eng.usf.edu \\ Received 25 August 2008; Accepted 25 November 2008 \\ Recommended by Rakesh Joshi
}

$\mathrm{ZnO}$ nanowire arrays were grown on a $\mathrm{Si}(100)$ substrate using the vapor-liquid-solid (VLS) method. ZnO nanowires were characterized by XRD, SEM, bright field TEM, and EDS. They were found to have a preferential orientation along the $c$-axis. The asprepared sample was functionalized with glucose oxidase by physical adsorption. FTIR was taken before and after functionalization to verify the presence of the attached enzyme. Electrochemical measurements were performed on the nanowire array by differential pulse voltammetry in the range of -0.6 to $0.4 \mathrm{~V}$. The nanoarray sensor displayed high sensitivity to glucose in the range of $1.0 \times 10^{-4}$ to $1.0 \times 10^{-2} \mathrm{~mol} \mathrm{~L}^{-1}$.

Copyright (c) 2008 Jessica Weber et al. This is an open access article distributed under the Creative Commons Attribution License, which permits unrestricted use, distribution, and reproduction in any medium, provided the original work is properly cited.

\section{INTRODUCTION}

One-dimensional metal-oxide nanostructures have gained prominence after the immense interest developed in the synthesis of carbon nanotubes and its wide range of applications [1]. Metal oxides such as $\mathrm{SnO}_{2}$ [2], $\mathrm{TiO}_{2}$ [3], $\mathrm{In}_{2} \mathrm{O}_{3}$ [4], ITO [5], $\mathrm{Ga}_{2} \mathrm{O}_{3}$ [6], and $\mathrm{ZnO}$ [7] have been synthesized into nanowires, nanorods, nanobelts, and nanohelices. Due to their excellent electronic and optical properties, they are widely found in transparent electronic devices [8], flat panel displays [9], field emitters [10], electrochemical sensors, and toxic gas sensors [11]. As a biocompatible semiconducting material, $\mathrm{ZnO}$ is being actively investigated for biosensor applications [12-14].

Miniaturization is one ongoing important development in biosensor technology. Miniaturization, however, may result in low current because of the decreased amount of immobilized enzyme onto the available active area. It has already been reported that nanostructures can enhance the sensitivity of a biosensor by one to two orders of magnitude, due to the large surface area per unit volume ratio, which allows the immobilization of a larger amount of the enzyme. Since the development of the first glucose sensor enzyme electrode performance, stability and selectivity have been a main thrust for further research [15]. The incorporation of biomolecules into carbon nanotubes (CNTs) and metal oxide nanowires is achieved through various methods of immobilization such as covalent linkage [16], entrapment [17], cross-linking with glutaraldehyde [18], microencapsulation [19], and adsorption [20-22]. Adsorption is one of the more common schemes of immobilization because it is a method that requires minimal preparation. In this work, prolonged exposure of glucose oxidase to $\mathrm{ZnO}$ nanowires has resulted in enzyme immobilization through nonspecific adsorption of the enzyme on the sidewalls of the nanowires. This letter reports on the synthesis and characterization of $\mathrm{ZnO}$ nanowires by vapor-liquid-solid (VLS) mechanism and its application as an electrode for glucose measurement without any additional protective coating.

\section{METHODS AND MATERIALS}

For the growth of $\mathrm{ZnO}$ nanowires, $\mathrm{ZnO}$ nanopowder (99.999\%, Sigma $\sim 50-70 \mathrm{~nm}$ grain size) and graphite nanopowder $(99.99 \%$, Sigma $\sim 70 \mathrm{~nm})$ in $1: 1$ ratio were mixed to form a homogenous source weighing $300 \mathrm{mg}$. For the amperometric glucose detection, glucose oxidase (GOX, EC 1.1.3.4, type II from Aspergillus niger, $47200 \mathrm{U} / \mathrm{g}$ ), 
D-(+)-glucose (purity 99.5\%), and potassium phosphate were purchased from Sigma-Aldrich, St. Louis, Mo, USA. Phosphate buffer electrolyte solutions (PBSs) with various $\mathrm{pH}$ were prepared from standard stock solutions of $\mathrm{KH}_{2} \mathrm{PO}_{4}$ and $\mathrm{K}_{2} \mathrm{HPO}_{4}$. All solutions were prepared with deionized water.

A high temperature furnace (Lindberg/Blue) was used for the growth of $\mathrm{ZnO}$ nanowires. As synthesized products were characterized by $\mathrm{X}$-ray diffraction with $\mathrm{Cu}-\mathrm{K} \alpha$ radiation (Philips X'pert Pro diffractometer), field emission scanning electron microscopy (FE-SEM, Hitachi S-800), and highresolution transmission electron microscopy (FEI Tecnai F30, HR-TEM). TEM specimens were prepared by ultrasonicating the $\mathrm{ZnO}$ nanowires in methanol and dispersing a drop of solution on a carbon-coated copper grid. Chemical compositional analysis was carried out by EDX coupled with the HR-TEM system.

Electrochemical experiments were performed using a Princeton Applied Research PARSTAT 2263 advanced electrochemical analyzer. All electrochemical measurements were executed in a standard three-electrode system at room temperature. The modified zinc oxide sample acted as the working electrode, with an $\mathrm{Ag} / \mathrm{AgCl}(3 \mathrm{M} \mathrm{KCl})$ reference electrode, and a platinum wire (CH Instruments, Tex, USA) counter electrode. All potentials given in this paper are relative to the $\mathrm{Ag} / \mathrm{AgCl}$ electrode. The $\mathrm{pH}$ of the glucose solutions was measured with a Fisher Scientific AB15 pH meter. FTIR studies were performed on a Perkin-Elmer Spectrum One FT-IR Spectrometer.

For the fabrication of a glucose sensor, we have initially grown an array of $\mathrm{ZnO}$ nanowires on $\mathrm{Si}$ (100) via thermal evaporation, with the use of a gold catalyst. Freshly prepared $\mathrm{ZnO}$ source powder and substrates were loaded in two different alumina boats in the high-temperature and lowtemperature zones of the vacuum furnace, respectively. The furnace was initially evacuated to a pressure of $10^{-3}$ Torr and argon was then passed at a constant flow rate of $500 \mathrm{sccm}$. The temperature of the furnace was approximately raised to $900^{\circ} \mathrm{C}-950^{\circ} \mathrm{C}$. The substrates were unloaded after the furnace was cooled to room temperature. The zinc oxide nanowire array was then functionalized with the enzyme glucose oxidase. Approximately 15 IU of GOX was applied onto the nanowire surface via physical adsorption. The newly constructed electrode was allowed to dry over 24 hours at room temperature prior to use.

\section{RESULTS AND DISCUSSION}

The X-ray diffraction pattern of the as-grown $\mathrm{ZnO}$ products is shown in Figure 1. All the visible peaks are indexed to a wurtzite (hexagonal) structure of $\mathrm{ZnO}$ with lattice constants of $a=0.3250 \mathrm{~nm}$ and $c=0.5205 \mathrm{~nm}$, respectively [23]. A small shift was observed in the peaks of $\mathrm{ZnO}$ nanowires when compared to $\mathrm{ZnO}$ bulk. This might be due to the thermal stresses developed at the time of growth. In addition, Au (111) and $\mathrm{Au}$ (200) peaks were also detected from the XRD pattern. The high intensity of (002) peak of $\mathrm{ZnO}$ nanowires shows that the preferential growth direction is along the $c$ axis.

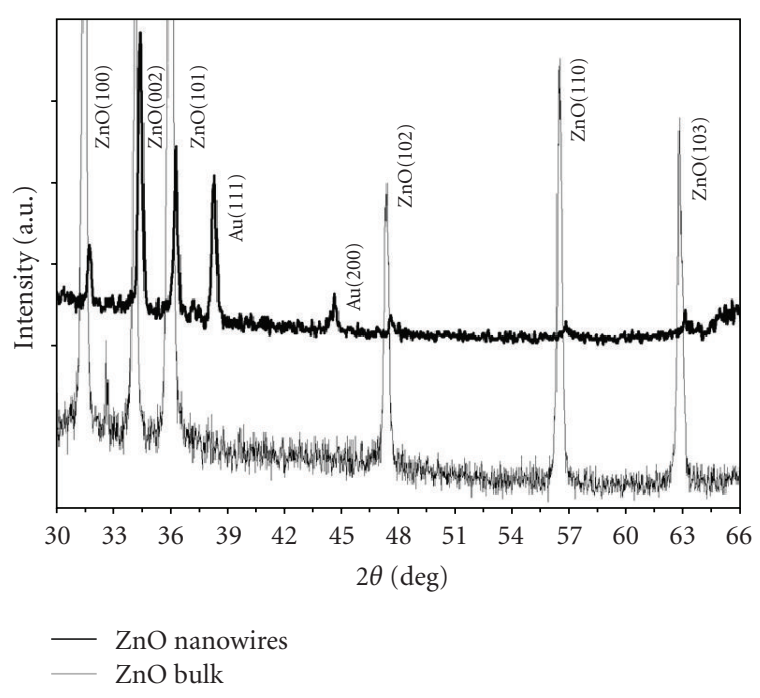

FIgURE 1: (upper curve) X-ray diffraction spectrum of an array of $\mathrm{ZnO}$ nanotubular structures and (lower curve) bulk $\mathrm{ZnO}$, respectively.

The surface morphology of the patterned sample can be observed in the SEM images (see Figure 2). The $\mathrm{ZnO}$ nanowires have a typical length of $0.5-2 \mu \mathrm{m}$ and a diameter of $40-120 \mathrm{~nm}$. Figure 3 shows the TEM image of a pair of nanowires and inset shows the electron diffraction pattern of the wires. It is clearly shown from the electron diffraction pattern that the one-dimensional nanowires were single crystal and grown along [0001]. A representative energy dispersive X-ray (EDX) spectrum was performed near the tip of the $\mathrm{ZnO}$ nanowire as indicated by the arrow shown in Figure 3(c). The peaks associated with $\mathrm{Zn}, \mathrm{O}, \mathrm{Au}, \mathrm{Cu}$, and $\mathrm{C}$ are seen in the EDX spectrum, where the peak corresponding to $\mathrm{Au}$ confirms that the tips of the nanowires were encapsulated with a gold particle of diameter $\sim 52 \mathrm{~nm}$ (see Figure 3(c)) and the copper and carbon signatures are from the carbon-coated copper TEM grid.

The as-grown $\mathrm{ZnO}$ nanowires on silicon substrate were analyzed by Fourier transform infrared (FTIR) spectroscopy before and after functionalization with GOX (see Figure 4). The absorption peak at about $1000 \mathrm{~cm}^{-1}$ can be interpreted as the Si-O-Zn vibrational mode [24]. GOX is seen through the presence of the primary amine group. The $\mathrm{N}-\mathrm{H}$ bending is observed at $1600 \mathrm{~cm}^{-1}$ while the $\mathrm{N}-\mathrm{H}$ stretch due to asymmetric and symmetric vibrations occurs at $3400 \mathrm{~cm}^{-1}$ and $3300 \mathrm{~cm}^{-1}$, respectively. The activity of the enzyme glucose oxidase is affected by the $\mathrm{pH}$ of the glucose solution. The $\mathrm{pH}$ dependence of the sensor was evaluated at $5 \mathrm{mM}$ glucose solutions in the range of $\mathrm{pH} 6$ to 9 (see Figure 5). An optimal peak current of the sensor was displayed at $\mathrm{pH}$ 6.5. Considering that the $\mathrm{pH}$ of human blood is about 7.4, the amperometric experiments were performed at $\mathrm{pH}$ 7.0. Figure 6 shows the cyclic voltammograms of the $\mathrm{ZnO}-\mathrm{GOX}$ electrode in PBS at a $\mathrm{pH}$ of 7.0 and at room temperature. The inset shows the plot of peak current versus the square root of the scan rate. The plot is nearly linear with less than $3 \%$ error from 50 to $400 \mathrm{mV} \mathrm{s}^{-1}$. The decrease in current response 


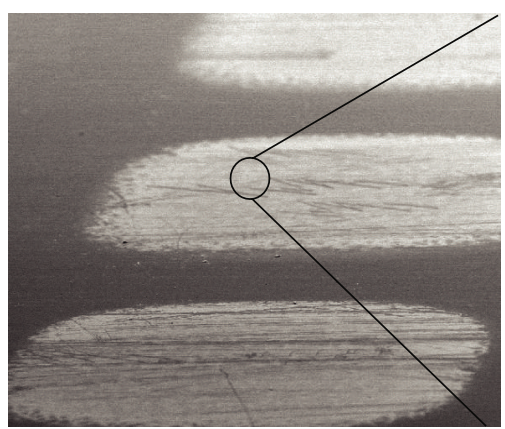

$\mathrm{ZnO}$ nanowires $25 \mathrm{kV} \times 161100 \mu \mathrm{m}$

(a)

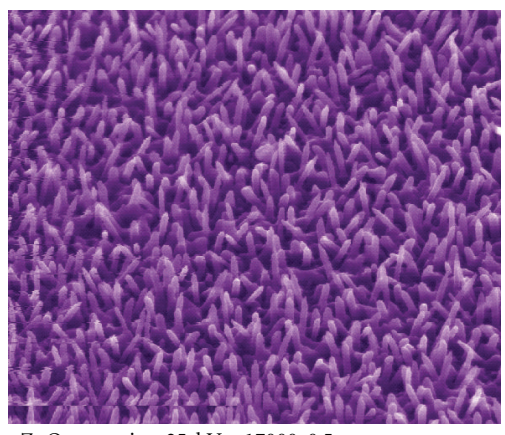

$\mathrm{ZnO}$ nanowires $25 \mathrm{kV} \times 170000.5 \mu \mathrm{m}$

(c)

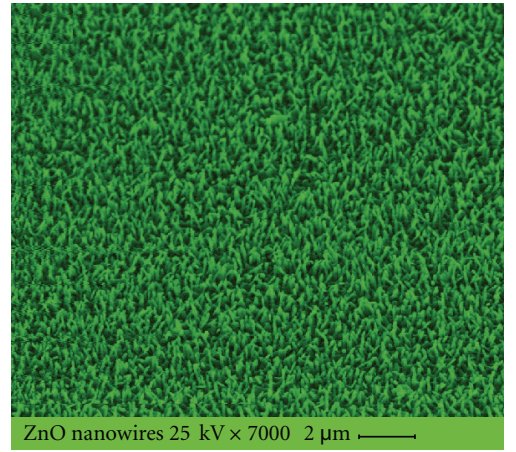

(b)

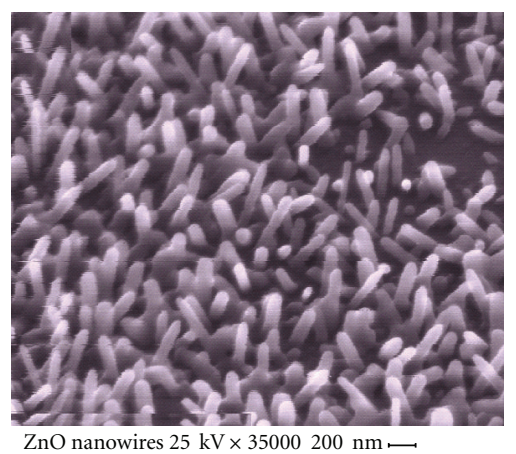

(d)

FIgure 2: (a) Low magnification top-view SEM image of patterned $\mathrm{ZnO}$ nanotubes. (b-d) Side view of patterned- and aligned-ZnO nanotubes from lower to higher magnification (clockwise direction).

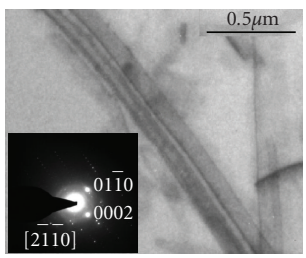

(a)

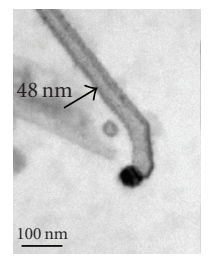

(b)

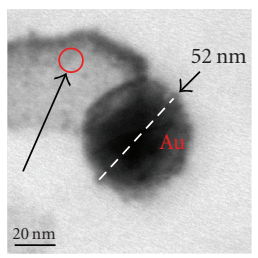

(c)

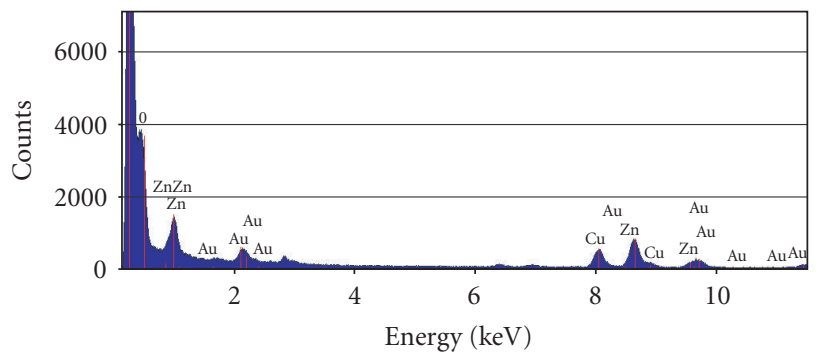

- EDX HAADF detector point 1

(d)

Figure 3: (a) Bright field TEM image of a pair of $\mathrm{ZnO}$ nanotubes, inset shows electron diffraction pattern on a pair of $\mathrm{ZnO}$ nanotubes along the zone axis $\left[\begin{array}{lll}2 & 11 & 0\end{array}\right]$. (b) TEM image of a $\mathrm{ZnO}$ nanotube with an Au particle at the end. (c) Shows high-resolution image of the end of the $\mathrm{ZnO}$ nanotube. (d) EDS spectrum recorded near the catalyst particle indicated by arrow.

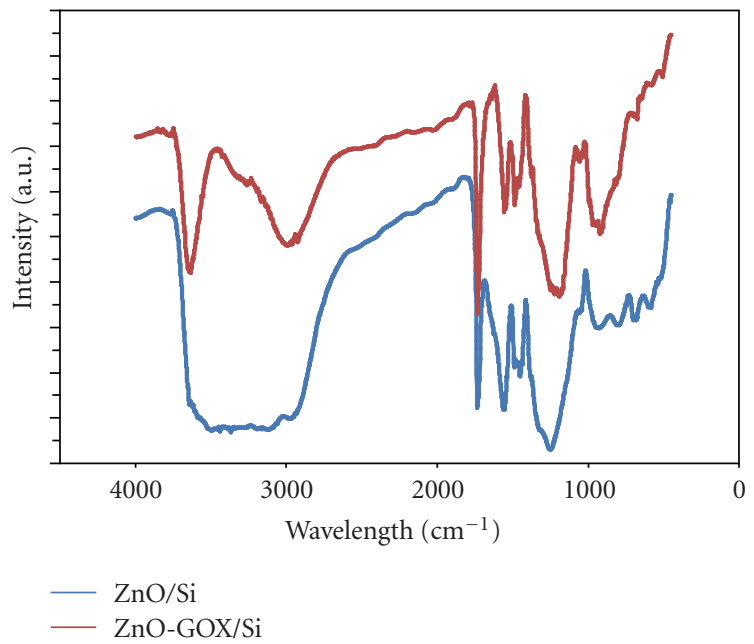

Figure 4: FTIR spectra of (lower curve) $\mathrm{ZnO}$ nanowires and (upper curve) glucose oxidase entrapped-ZnO nanowires, onto $\mathrm{Si}$ substrate.

with successive increase in scan rate indicates that the electrode reaction is diffusion controlled. The direct pulse voltammetry (DPV) response of the sensor to successive increments of glucose is shown in Figure 7(a). These results were obtained with a scan rate of $0.020 \mathrm{mV} / \mathrm{s}$, step height 


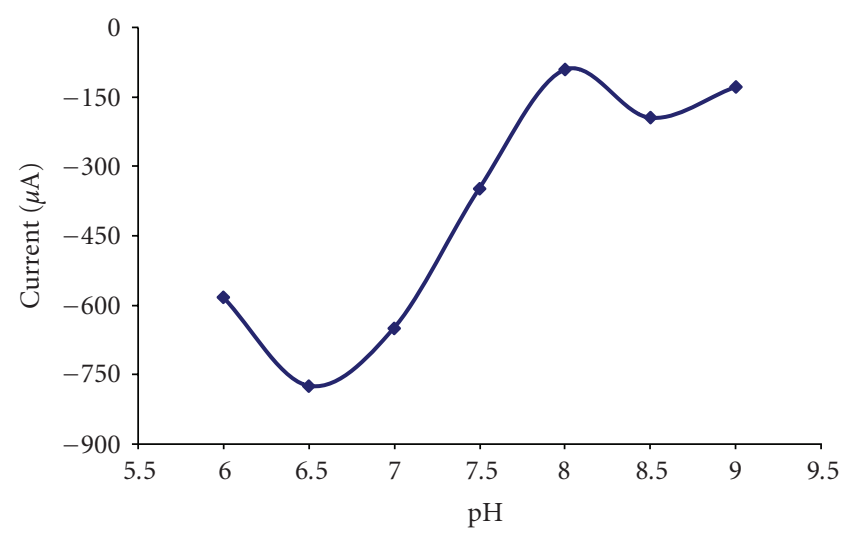

Figure 5: Current response of $\mathrm{ZnO}$-based glucose sensor in PBS with increasing $\mathrm{pH}$ containing $5.0 \times 10^{-3} \mathrm{~mol} \mathrm{~L}^{-1}$ glucose.

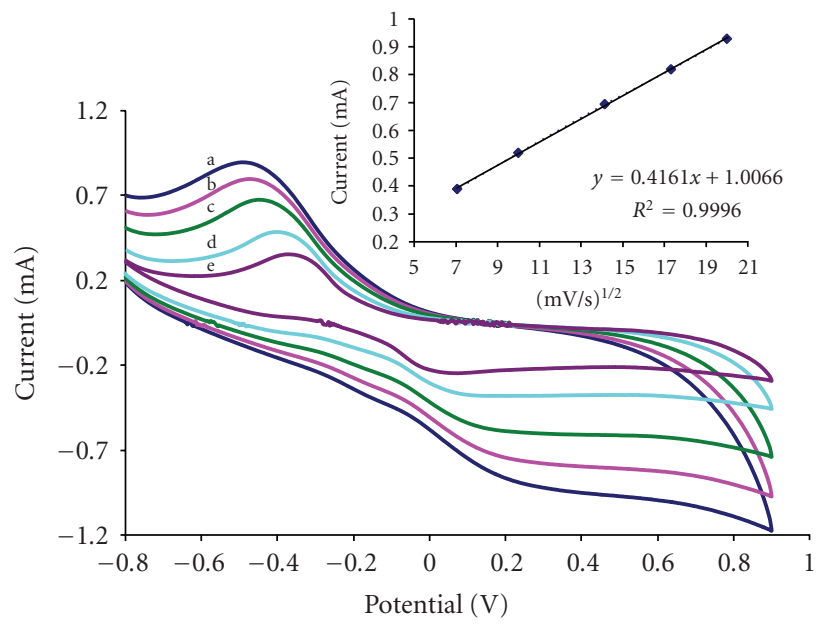

FIgUre 6: Cyclic voltammograms of ZnO-GOX/Si in PBS ( $\mathrm{pH} 7.0$ ) containing $5.0 \times 10^{-3} \mathrm{~mol} \mathrm{~L}^{-1}$ glucose at a scan rate of (a) $50 \mathrm{mV} \mathrm{s}^{-1}$, (b) $100 \mathrm{mV} \mathrm{s}^{-1}$, (c) $200 \mathrm{mV} \mathrm{s}^{-1}$, (d) $300 \mathrm{mV} \mathrm{s}^{-1}$, and (e) $400 \mathrm{mV} \mathrm{s}^{-1}$. Inset plot: relationship between scan rate and response current of ZnO-GOX/Si in PBS (pH 7.0) containing $5.0 \times 10^{-3} \mathrm{~mol} \mathrm{~L}^{-1}$ glucose.

of $2 \mathrm{mV}$, and a potential sweep between -0.6 and $0.4 \mathrm{~V}$. The well-defined peaks occur at approximately $-0.05 \mathrm{~V}$, showing that the enzyme is active at this potential. This data displays a linear relationship of current to the corresponding glucose concentration. The calibration response curve (see Figure $7(\mathrm{~b}))$ shows a linear trend in the range of $1.0 \times 10^{-4}$ to $1.0 \times 10^{-2} \mathrm{~mol} \mathrm{~L}^{-1}$ glucose with an $r$-value of 0.9903 and less than $5 \%$ error.

\section{CONCLUSIONS}

The successful fabrication of a highly selective $\mathrm{ZnO}$ nanowire-based amperometric glucose biosensor has been achieved. The $\mathrm{ZnO}$ electrodes were synthesized on Si (100) substrates by VLS mechanism. High-density $\mathrm{ZnO}$ nanowires with a large surface area are found to have a preferential growth direction along [0001] axis. No additional protective coating has been utilized during the electrode preparation.

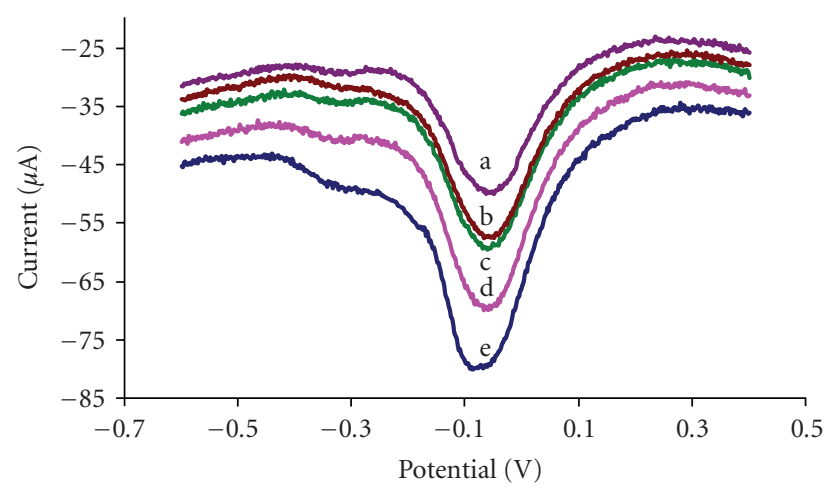

(a)

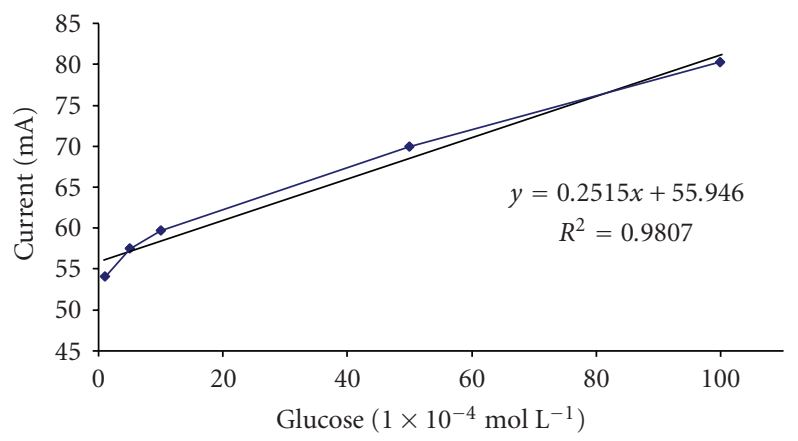

(b)

Figure 7: (a) DPV response of $\mathrm{ZnO}-\mathrm{GOX} / \mathrm{Si}$ in PBS ( $\mathrm{pH}$ 7.0) at (a) $1 \times 10^{-4} \mathrm{~mol} \mathrm{~L}^{-1}$, (b) $5 \times 10^{-4} \mathrm{~mol} \mathrm{~L}^{-1}$, (c) $1 \times 10^{-3} \mathrm{~mol} \mathrm{~L}^{-1}$, (d) $5 \times 10^{-3} \mathrm{~mol} \mathrm{~L}^{-1}$, and (e) $1 \times 10^{-2} \mathrm{~mol} \mathrm{~L}^{-1}$ glucose. (b) Linear calibration curve of $\mathrm{ZnO}-\mathrm{GOX}$ biosensor.

The sensor functioned in the range of $1.0 \times 10^{-4}$ to $1.0 \times 10^{-2} \mathrm{~mol} \mathrm{~L}^{-1}$ glucose. The biosafe nature of $\mathrm{ZnO}$ and successful immobilization of glucose oxidase onto the electrode surface leads to a new novel approach to biosensor construction and applications.

\section{ACKNOWLEDGMENTS}

The authors would like to acknowledge the generous support of the National Science Foundation. This research was supported by the following National Science Foundation (NSF) grants: NIRT no. 0404137, Crest no. 0734232, IGERT no. 0221681 , and GK12 no. 0638709.

\section{REFERENCES}

[1] N. Hamada, S.-I. Sawada, and A. Oshiyama, "New onedimensional conductors: graphitic microtubules," Physical Review Letters, vol. 68, no. 10, pp. 1579-1581, 1992.

[2] J. Zhang, F. Jiang, and L. Zhang, "Synthesis of $\mathrm{SnO}_{2}$ nanobelts and their structural characterization," Journal of Physics D, vol. 36, no. 2, pp. L21-L24, 2003.

[3] B. Xiang, Y. Zhang, Z. Wang, et al., "Field-emission properties of $\mathrm{TiO}_{2}$ nanowire arrays," Journal of Physics D, vol. 38, no. 8, pp. 1152-1155, 2005.

[4] C. Li, D. Zhang, X. Liu, et al., " $\operatorname{In}_{2} \mathrm{O}_{3}$ nanowires as chemical sensors," Applied Physics Letters, vol. 82, no. 10, pp. 1613-1615, 2003. 
[5] D. Yu, D. Wang, W. Yu, and Y. Qian, "Synthesis of ITO nanowires and nanorods with corundum structure by a coprecipitation-anneal method," Materials Letters, vol. 58, no. 12, pp. 84-87, 2004.

[6] K.-W. Chang and J.-J. Wu, "Formation of $\beta-\mathrm{Ga}_{2} \mathrm{O}_{3}-\mathrm{TiO}_{2}$ 'nanobarcodes' from core-shell nanowires," Advanced Materials, vol. 17, no. 2, pp. 241-245, 2005.

[7] D. Banerjee, J. Rybczynski, J. Y. Huang, D. Z. Wang, K. Kempa, and Z. F. Ren, "Large hexagonal arrays of aligned $\mathrm{ZnO}$ nanorods," Applied Physics A, vol. 80, no. 4, pp. 749-752, 2005.

[8] J. P. Santos and J. A. de Agapito, "The interaction of oxygen with nanocrystalline $\mathrm{SnO}_{2}$ thin films in the framework of the electron theory of adsorption," Thin Solid Films, vol. 338, no. 1-2, pp. 276-280, 1999.

[9] T. Mahalingam, V. S. John, M. Raja, Y. K. Su, and P. J. Sebastian, "Electrodeposition and characterization of transparent $\mathrm{ZnO}$ thin films," Solar Energy Materials and Solar Cells, vol. 88, no. 2, pp. 227-235, 2005.

[10] C. J. Lee, T. J. Lee, S. C. Lyu, Y. Zhang, H. Ruh, and H. J. Lee, "Field emission from well-aligned zinc oxide nanowires grown at low temperature," Applied Physics Letters, vol. 81, no. 19, p. 3648, 2002.

[11] J. Ding, T. J. McAvoy, R. E. Cavicchi, and S. Semancik, "Surface state trapping models for $\mathrm{SnO}_{2}$-based microhotplate sensors," Sensors and Actuators B, vol. 77, no. 3, pp. 597-613, 2001.

[12] Q. Wan, Q. H. Li, Y. J. Chen, et al., "Fabrication and ethanol sensing characteristics of $\mathrm{ZnO}$ nanowire gas sensors," Applied Physics Letters, vol. 84, no. 18, pp. 3654-3656, 2004.

[13] B. S. Kang, F. Ren, Y. W. Heo, L. C. Tien, D. P. Norton, and S. J. Pearton, " $p \mathrm{H}$ measurements with single $\mathrm{ZnO}$ nanorods integrated with a microchannel," Applied Physics Letters, vol. 86, no. 11, Article ID 112105, 3 pages, 2005.

[14] F. Zhang, X. Wang, S. Ai, et al., "Immobilization of uricase on $\mathrm{ZnO}$ nanorods for a reagentless uric acid biosensor," Analytica Chimica Acta, vol. 519, no. 2, pp. 155-160, 2004.

[15] L. C. Clark and C. Lyons, "Electrode systems for continuous monitoring in cardiovascular surgery," Annals of the New York Academy of Sciences, vol. 102, pp. 29-45, 1962.

[16] M. A. Rahman, D.-S. Park, and Y.-B. Shim, "A performance comparison of choline biosensors: anodic or cathodic detections of $\mathrm{H}_{2} \mathrm{O}_{2}$ generated by enzyme immobilized on a conducting polymer," Biosensors and Bioelectronics, vol. 19, no. 12, pp. 1565-1571, 2004.

[17] J. C. Vidal, E. Garcia-Ruiz, J. Espuelas, T. Aramendia, and J. R. Castillo, "Comparison of biosensors based on entrapment of cholesterol oxidase and cholesterol esterase in electropolymerized films of polypyrrole and diaminonaphthalene derivatives for amperometric determination of cholesterol," Analytical and Bioanalytical Chemistry, vol. 377, no. 2, pp. 273-280, 2003.

[18] J.-J. Xu, D.-M. Zhou, and H.-Y. Chen, "A reagentless hydrogen peroxide biosensor based on the coimmobilization of thionine and horseradish peroxidase by their cross-linking with glutaraldehyde on glassy carbon electrode," Electroanalysis, vol. 10, no. 10, pp. 713-716, 1998.

[19] D. Trau and R. Renneberg, "Encapsulation of glucose oxidase microparticles within a nanoscale layer-by-layer film: immobilization and biosensor applications," Biosensors and Bioelectronics, vol. 18, no. 12, pp. 1491-1499, 2003.

[20] R. J. Chen, Y. Zhang, D. Wang, and H. Dai, "Noncovalent sidewall functionalization of single-walled carbon nanotubes for protein immobilization," Journal of the American Chemical Society, vol. 123, no. 16, pp. 3838-3839, 2001.
[21] R. F. Lane and A. T. Hubbard, "Electrochemistry of chemisorbed molecules-I. Reactants connected to electrodes through olefinic substituents," Journal of Physical Chemistry, vol. 77, no. 11, pp. 1401-1410, 1973.

[22] R. F. Lane and A. T. Hubbard, "Electrochemistry of chemisorbed molecules-II. Influence of charged chemisorbed molecules on the electrode reactions of platinum complexes," Journal of Physical Chemistry, vol. 77, no. 11, pp. 1411-1421, 1973.

[23] K. Park, J.-S. Lee, M.-Y. Sung, and S. Kim, "Structural and optical properties of ZNO nanowires synthesized from ballmilled ZNO powders," Japanese Journal of Applied Physics Part 1, vol. 41, no. 12, pp. 7317-7321, 2002.

[24] J. P. Rainho, J. Rocha, L. D. Carlos, and R. M. Almeida, " ${ }^{29} \mathrm{Si}$ nuclear-magnetic-resonance and vibrational spectroscopy studies of $\mathrm{SiO}_{2}-\mathrm{TiO}_{2}$ powders prepared by the sol-gel process," Journal of Materials Research, vol. 16, no. 8, pp. 2369-2376, 2001. 

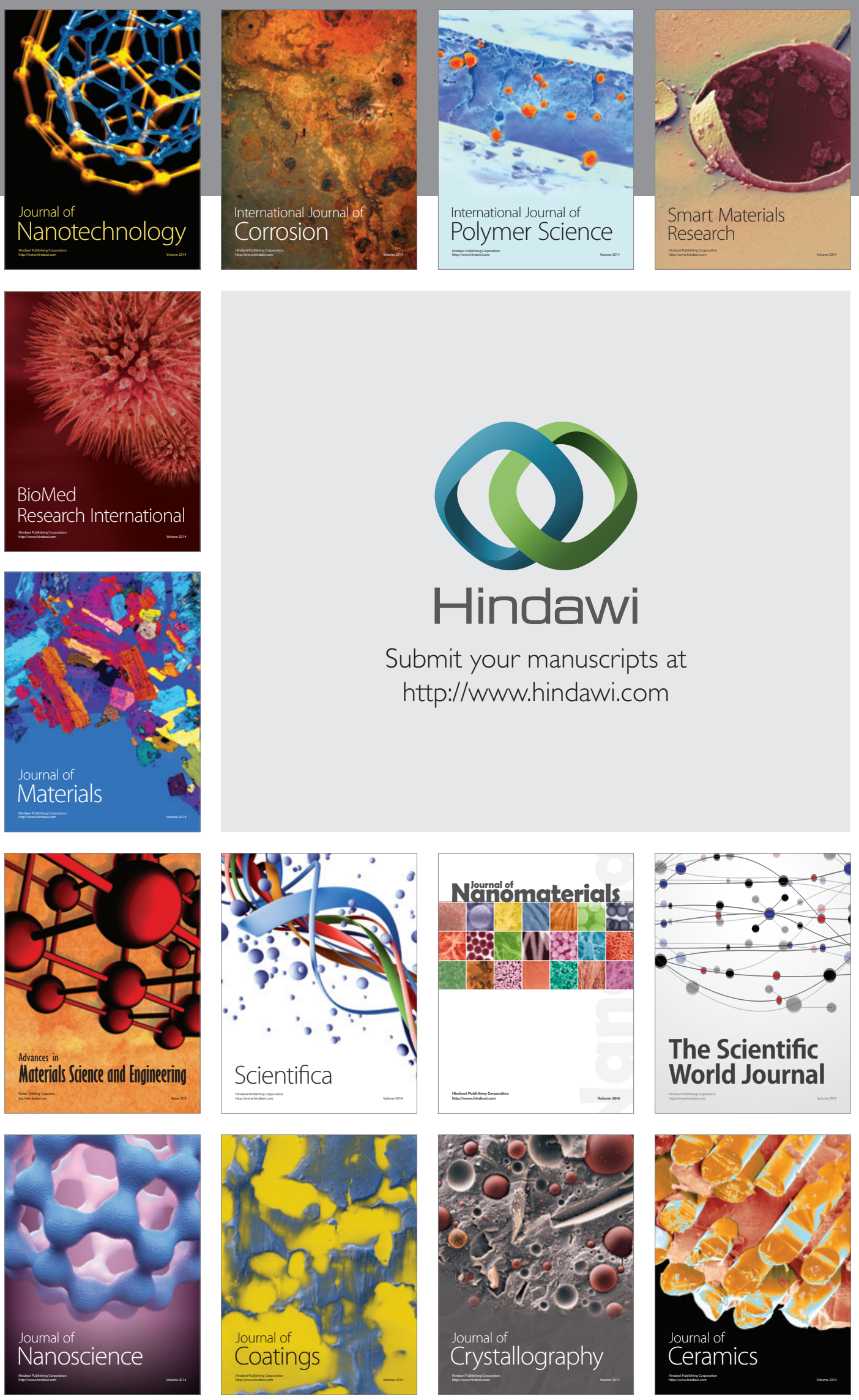

The Scientific World Journal

Submit your manuscripts at

http://www.hindawi.com

\section{World Journal}

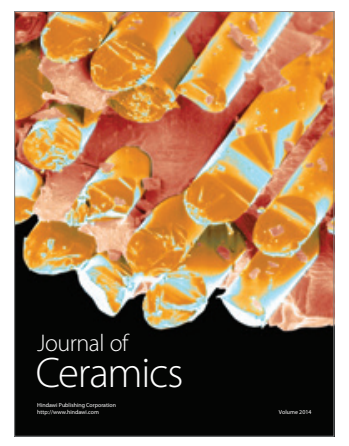

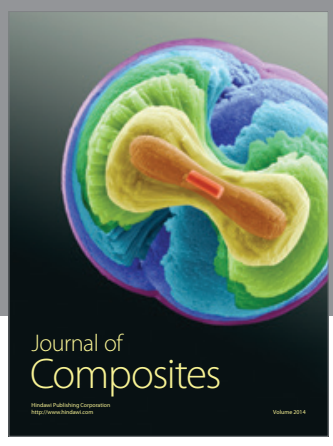
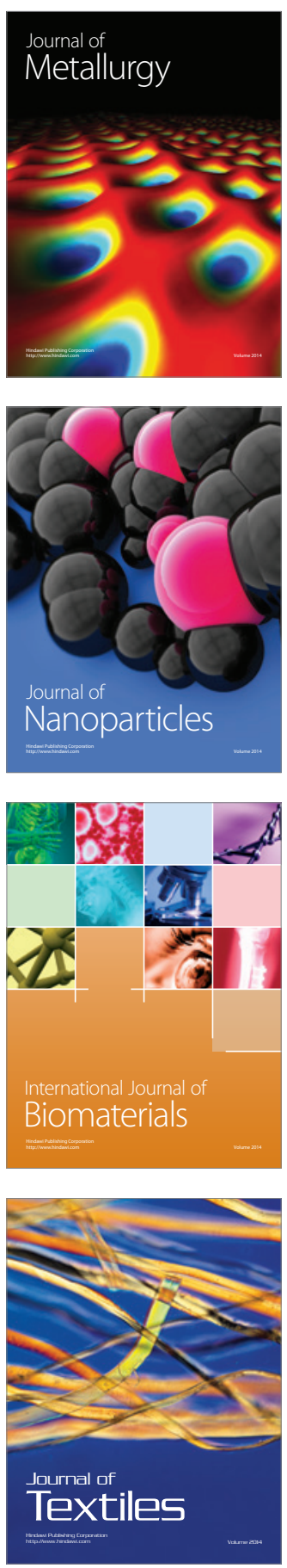